\title{
PROPOSTA DE ESTUDO LITERÁRIO A PARTIR DA PERSPECTIVA DA PEDAGOGIA DOS MULTILETRAMENTOS E DE REFLEXÕES ACERCA DO ENSINO HÍBRIDO
}

\author{
PROPUESTA DE ESTUDIO LITERARIO DESDE LA PERSPECTIVA DE LA \\ MULTILITERACIDAD PEDAGÓGICA Y REFLEXIONES SOBRE LA ENSEÑANZA \\ HÍBRIDA
}

Ana Rita de Souza dos Santos ${ }^{1}$ Veruska Ribeiro Machado ${ }^{2}$

\begin{abstract}
Resumo: Os novos comportamentos e formas de comunicação refletem na escola e alteram o modelo de educação existente, colocando o(a) educador(a) e o(a) estudante diante de um novo contexto, caracterizado por múltiplos canais de comunicação, múltiplas linguagens e novas formas de interação. Ante esses desafios, acredita-se que um currículo que tenha os multiletramentos como princípio estruturador poderá atender a algumas competências essenciais da educação básica. Para tanto, este relato apresenta uma adaptação de sequência didática realizada a partir de uma pesquisa que buscou identificar a perspectiva de ensino de língua portuguesa de professores(as) de uma instituição pública que oferta ensino médio. Na sequência aqui apresentada, os(as) estudantes são convidados(as) a conhecer o fanzine, que é uma revista criada por fãs, de forma independente, para outros fãs, acerca de um determinado tema em comum - gênero comum na cultura digital. 0 material final da oficina foram fanzines produzidos com base na retextualização de contos de Machado de Assis. Verificou-se, a partir dessa experiência, que, ao produzirem seu próprio fanzine, os(as) estudantes privilegiaram o uso de uma linguagem mais próxima do cotidiano. A sequência didática, elaborada a partir dos resultados da pesquisa, está pautada nos parâmetros da pedagogia dos multiletramentos e procura contemplar, de forma significativa, as necessidades da sala de aula no contexto diário de aulas de literatura.
\end{abstract}

Palavras-chave: multiletramentos, literatura, cultura digital, ensino médio.

Resumen: Los nuevos comportamientos y formas de comunicación se reflejan en la escuela y alteran el modelo educativo existente, colocando al educador y al estudiante en un nuevo contexto, caracterizado por múltiples canales de comunicación, múltiples idiomas y nuevas formas de interacción Ante estos desafíos, se cree que un plan de estudios que tiene la multiliteracidad como principio estructurante puede cumplir con algunas habilidades esenciales de la educación básica. Con este fin, este informe presenta una adaptación de la secuencia didáctica realizada a partir de una investigación que buscó identificar la perspectiva de la enseñanza del idioma portugués por parte de docentes de una institución pública que ofrece educación secundaria. En la secuencia presentada aquí, se invita a los estudiantes a descubrir el fanzine, que es una revista creada por fanáticos, independientemente, para otros fanáticos, sobre un tema en común: un género común en la cultura digital. El material final del taller fue fanzines producidos en base a la retextualización de historias de Machado de Assis. Se comprobó, a partir de esta experiencia, que, al producir su propio fanzine, los estudiantes privilegiaban el uso de un lenguaje más cercano a la vida cotidiana. A partir de estos resultados, fue posible elaborar una secuencia didáctica basada en los parámetros de la multiliteracidad pedagógica, pero que contemplaba significativamente las necesidades del aula en el contexto diario de las clases de literatura.

Palabra clave: multiliteracidad, literatura, cultura digital, escuela secundaria.

\footnotetext{
${ }^{1}$ Graduanda em Letras - Língua Portuguesa pelo Instituto Federal de Brasília - campus São Sebastião. Foi bolsista pelo Projeto de Iniciação Científica intitulada "Pedagogia dos Multiletramentos como alternativa para o ensino de língua portuguesa no ensino médio" (FAP - DF 2019/2020). Atualmente é corretora de textos pelo colégio La Salle - Águas Claras e professora de Língua Portuguesa e humanidades pelo Projeto Consciência - DF, no Centro de Ensino Fundamental 507 de Samambaia. Orcid: https://orcid.org/0000-0002-1487-293X

${ }^{2}$ Doutora em Educação pela Universidade de Brasília. Docente de Língua Portuguesa de Ensino Básico, Técnico e Tecnológico no Instituto Federal de Brasília. É também docente do Programa de Mestrado Profissional em Educação Profissional da Rede Federal de Educação Profissional, Científica e Tecnológica, atuando na linha Práticas Educativas em Educação Profissional e Tecnológica. https://orcid.org/0000-0002-7754-6947
}

Rev. Nova Paideia - Revista Interdisciplinar em Educação e Pesquisa Brasília/DF, v. 2, n. 1. p. 64 - 86 - ANO 2020 ISSN 2674-5976 


\section{Introdução}

O termo letramento foi utilizado pela primeira vez no Brasil por Mary Kato em 1986, mas apenas em 1988 Leda Tfouni dedica-se à definição desse termo, que passa, então, a ser usado no Brasil, desde o final da década de 80, principalmente, para denominar o processo de desenvolvimento da capacidade de uso proficiente da linguagem, especialmente a escrita.

0 conceito de letramento, dessa forma, não se restringe ao uso da linguagem para a aquisição de conhecimento. Parte-se da concepção de que o desenvolvimento de habilidades de leitura e escrita tem natureza plural, evidenciada tanto nas práticas individuais quanto no uso comunitário. Em linhas gerais, o letramento envolve a capacidade de o indivíduo usar informações escritas para atingir seus objetivos.

Mais recentemente, essa perspectiva foi ampliada, dando espaço para uma pedagogia dos multiletramentos. Considera-se aqui multiletramentos na escola na perspectiva de Roxane Rojo e Eduardo Moura. Rojo e Moura (2012) propõem atividades, mediadas pelo uso de novas tecnologias digitais, de leitura crítica, análise e produção de textos multissemióticos com enfoque multicultural, utilizando a perspectiva dos multiletramentos. Essa ampliação vai ao encontro das mudanças sociais vivenciadas mais intensamente nas duas últimas décadas. Para Pereira (2016), essas novas concepções se baseiam

no princípio de que as mudanças contemporâneas impactaram as atividades em quase todas as principais áreas da vida, na sociedade moderna, transformando práticas sociais já estabelecidas e ocasionando o surgimento de outras, sendo que muitas destas envolvem novas formas de produzir e receber textos por meios eletrônicos, a maioria de tais textos incluindo formas multimodais (Pereira, 2016, p. 160).

Considerando a pedagogia dos multiletramentos, Rojo (2017) discute a importância de se pensar atividades que se articulem com um webcurrículo, na perspectiva dos multiletramentos, valorizando as múltiplas linguagens, o paradigma da aprendizagem interativa, o trabalho colaborativo, a agência e protagonismo do aluno.

Corroborando o pensamento de Rojo e Moura (2012), trabalhar em uma perspectiva da pedagogia dos multiletramentos não é simplesmente desenvolver um conjunto de habilidades individuais, mas sim um conjunto de práticas sociais, ligadas à leitura e à escrita, através de textos que abrangem, cada vez mais, os letramentos da letra, imagens e sons. Nesse sentido, parte-se do princípio de que é fulcral, em uma sociedade permeada pelas tecnologias digitais, desenvolver o letramento literário dos estudantes coadunado ao uso dessas tecnologias digitais, tendo em vista que a literatura é um campo múltiplo de entendimentos, com um caminho que deve ser percorrido de forma exploratória e facilitadora das habilidades de leitura. 
Em relação ao desenvolvimento do letramento literário nas práticas pedagógicas, o Ceale $^{3}$ aponta quatro características fundamentais: i) interação do estudante, leitor em formação, com as obras literárias; ii) constituição de um espaço de compartilhamento de leituras, com circulação de textos diversos; iii) ampliação do repertório literário, com a acolhida, no espaço escolas, das mais diversas manifestações culturais; iv) desenvolvimento de atividades sistematizadas e contínuas direcionadas para o desenvolvimento da competência literária. Essas características fundamentais contribuem para a formação do leitor literário no contexto escolar.

Essas características fundamentais para o desenvolvimento do letramento literário, somadas às novas práticas sociais discursivas, centradas nos meios eletrônicos (Pereira, 2016), demandam uma ressignificação do ensino de língua portuguesa no ensino médio, envolvendo o ensino da literatura. Pereira (2016) reforça que, nesse contexto, emergem novos paradigmas educacionais em relação ao desenvolvimento da leitura e da escrita.

Nesse sentido, considera-se aqui, neste relato, como base para a ressignificação das práticas pedagógicas, os multiletramentos na escola na perspectiva de Roxane Rojo e Eduardo Moura (2012), que propõem atividades mediadas pelo uso de novas tecnologias digitais, de leitura crítica, análise e produção de textos multissemióticos com enfoque multicultural. A multiplicidade implicada no termo multiletramentos, segundo os autores, refere-se às múltiplas culturas e à multiplicidade semiótica dos textos utilizados para informação e comunicação.

A proposta pedagógica aqui apresentada é fruto de uma pesquisa que buscou compreender e identificar a perspectiva de ensino de língua portuguesa de professores(as) de uma instituição pública que oferta ensino médio. 0 intuito do projeto, para além da investigação, foi desenvolver um percurso metodológico pautado na pedagogia dos multiletramentos. Para isso, fez-se indispensável pensar em formas de trabalho que abordem e utilizem tecnologias que proporcionem uma participação autônoma no processo de leitura da literatura e de escrita de textos artísticos e multissemióticos. Considerar a cultura digital e os multiletramentos, bem como compreender e perceber as diferentes práticas culturais, linguagens e interpretações críticas a respeito da realidade em que essas pessoas estão inseridas, faz parte de um grande movimento de inserção das práticas de linguagem do universo digital, compreendendo-o como nova possibilidade de produções autorais e de sentidos.

A partir dos resultados obtidos na investigação, a proposta procura ampliar as práticas de linguagem desenvolvidas nas aulas de língua portuguesa e realizar atividades de leitura, releitura e retextualização, considerando o contexto da cultura digital, na busca pelo desenvolvimento de habilidades de leitura do texto literário com

\footnotetext{
${ }^{3}$ Ver Glossário do Ceale. Disponível em:

http://www.ceale.fae.ufmg.br/app/webroot/glossarioceale/verbetes/letramento-literario. Consultado em: 01/06/2020.
}

Rev. Nova Paideia - Revista Interdisciplinar em Educação e Pesquisa Brasília/DF, v. 2, n. 1. p. 64 - 86 - ANO 2020 
base em temas como cânone literário, cultura popular, cultura de massa, remixagem, hibridismo e produção cultural.

\section{Percurso metodológico}

No período de vigência do projeto, foram desenvolvidas diversas oficinas de literatura na perspectiva da pedagogia dos multiletramentos. Esse grupo de oficinas foi intitulado "Leituras, Releituras e Retextualizações de Contos Machadianos à Luz da Pedagogia dos Multiletramentos". Essas oficinas foram elaboradas de forma que contemplassem os aspectos que envolvem a cultura digital e que pudessem ser desenvolvidas de forma on-line ou off-line. Para tanto, no presente relato, será possível visualizar a construção de uma sequência didática elaborada a partir da experiência vivida numa turma de $3^{\text {o }}$ ano do ensino médio que foi levada a estudar os contos machadianos.

A sequência didática proposta foi construída em uma perspectiva híbrida, combinando diferentes atividades, metodologias e aliando-se ao uso de tecnologias digitais. Bacich e Moran (2015) defendem que a educação sempre foi híbrida, visto que "sempre combinou vários espaços, tempos, atividades, metodologias, públicos". Segundo os autores, na contemporaneidade, "esse processo torna-se mais perceptível, amplo e profundo" devido à mobilidade e à conectividade (Bacich e Moran, 2015, p. 45).

As oficinas foram planejadas no formato de sequência didática, que corresponde a um conjunto de atividades articuladas que são planejadas com a intenção de atingir determinado objetivo didático (PESSOA, 2016, p. 37). A escolha do modelo de sequência didática a ser utilizado está relacionada aos objetivos que o(a) docente pretende alcançar diante das necessidades do grupo de estudantes. Neste trabalho, adotou-se a perspectiva sociointeracionista, que, segundo o Glossário Ceale ${ }^{4}$, baseia-se nos seguintes princípios didáticos:

valorização dos conhecimentos prévios dos alunos; ensino centrado na problematização; ensino reflexivo, com ênfase na explicitação verbal; ensino centrado na interação e na sistematização dos saberes; utilização de atividades diversificadas, desafiadoras e com possibilidade de progressão (das atividades mais simples às mais complexas) - lembrando que uma única atividade pode mobilizar diferentes conhecimentos e estimular diferentes habilidades.

A partir de uma sequência didática, o(a) professor(a) pode realizar um trabalho articulado em vários eixos de ensino, bem como organizar os(as) estudantes de diferentes maneiras (em pequenos grupos, duplas, individualmente ou

\footnotetext{
${ }^{4}$ Glossário Ceale. Disponível em:

http://www.ceale.fae.ufmg.br/app/webroot/glossarioceale/verbetes/sequencia-didatica
} 
coletivamente), de acordo com os objetivos didáticos e as necessidades dos(as) alunos(as), possibilitando aprendizagens diferentes.

Na elaboração da sequência, também foram consideradas as quatro características fundamentais para o desenvolvimento do letramento literário, apresentadas na introdução: interação com as obras literárias, compartilhamento de leituras, ampliação do repertório literário e atividades sistematizadas e contínuas.

A partir das sequências planejadas, foi possível trabalhar com o contexto da cultura participativa e colaborativa, o que trouxe autoria e autonomia para o grupo de estudantes que foi convidado a produzir e elaborar suas próprias retextualizações das obras estudadas.

As mudanças que atingem a escola em um mundo em constante transformação exigem um modelo dinâmico de aprendizagem que contemple o conhecimento e sua aplicação na vida real. Nesse sentido, a sequência aqui proposta parte do princípio de que é preciso, ante as novas práticas sociais e as novas formas de uso das linguagens, desenvolver o letramento literário considerando também os novos letramentos, incluindo a modalidade digital (Pereira, 2016).

\section{Proposta pedagógica}

Esta sequência didática possui o foco na esfera artístico-literária, trabalhando-a a partir da cultura digital e da exploração das tecnologias. Foi importante, para esse trabalho, compreender os contextos e as formas de lidar com os gêneros literários dentro de uma prática contemporânea, conhecer e utilizar-se de ferramentas on-line, materiais off-line já existentes e recursos educacionais abertos para que, assim, fosse possível unir de forma interdisciplinar as culturas, o mundo e a literatura.

A proposta de realizar atividades de leitura, releitura e retextualização de contos de Machado de Assis considerando o contexto da cultura digital almeja o desenvolvimento de habilidades de leitura crítica do texto literário.

\section{SEQUÊNCIA DIDÁTICA}

\section{Utilizando produções culturais de fanzines para adaptação do conto Um Homem} Célebre, de Machado de Assis 


\begin{tabular}{|c|c|}
\hline ÁREAS DE CONHECIMENTO & $\begin{array}{l}\text { Linguagens, códigos e suas } \\
\text { tecnologias. }\end{array}$ \\
\hline \multicolumn{2}{|c|}{ OBJETIVOS DE APRENDIZAGEM } \\
\hline \multicolumn{2}{|c|}{$\begin{array}{l}\text { - Desenvolver habilidades de leitura do texto literário, considerando as múltiplas } \\
\text { linguagens, culturas e tecnologias. } \\
\text { - Desenvolver autoria, criatividade e originalidade. } \\
\text { - Ressignificar criticamente a literatura no contexto contemporâneo. }\end{array}$} \\
\hline \multicolumn{2}{|c|}{ DURAÇÃO } \\
\hline \multicolumn{2}{|c|}{$\begin{array}{l}\text { Para a execução dessa proposta pedagógica, recomenda-se um planejamento de oito } \\
\text { horas. }\end{array}$} \\
\hline \multicolumn{2}{|c|}{ RECURSOS DIDÁTICOS } \\
\hline \multicolumn{2}{|c|}{$\begin{array}{l}\text { Computador, data show, caixa de som, jornais, fotos, textos impressos, fanzines, papéis, } \\
\text { tesoura, cola, caneta e enfeites diversos. }\end{array}$} \\
\hline \multicolumn{2}{|c|}{ METODOLOGIAS } \\
\hline $\begin{array}{l}\text { Sugere-se que essa sequência seja expl } \\
\text { construção de reflexões iniciais a respeit } \\
\text { introdução aos aspectos de retextualizaçã } \\
\text { elaboração e divulgação do produto final. } \\
\text { da exploração da vida e obra do autor do } \\
\text { do escritor, com o intuito de trabalhar } \\
\text { momento da leitura da obra. O segundo r } \\
\text { de retextualização, trabalho com cono } \\
\text { apresentação e os aspectos das fanzines } \\
\text { finalização da proposta, dedica-se à elab } \\
\text { trabalho realizado. } \\
\text { Os } 2 \text { núcleos iniciais contam com aulas e } \\
\text { trabalho é feito por meio de oficinas. Se } \\
\text { espaço de construção coletiva do conheci } \\
\text { troca de experiências. }\end{array}$ & $\begin{array}{l}\text { tir de } 3 \text { núcleos interligados: i) } \\
\text { tudada, contexto e relevância; ii) } \\
\text { em e apresentação do fanzine; iii) } \\
\text { discussão inicial acontece a partir } \\
\text { ido, como forma de apresentação } \\
\text { ssibilidades de interpretação no } \\
\text { a as novas formas e perspectivas } \\
\text { sibilidades. Trabalha-se com a } \\
\text { inal, de encaminhamento para a } \\
\text { etextualização e à divulgação do } \\
\text { alogadas e, para o núcleo final, o } \\
\text { au (1995), a oficina constitui um } \\
\text { álise da realidade, de confronto e }\end{array}$ \\
\hline
\end{tabular}

Núcleo 1: Construção de reflexões iniciais a respeito da obra estudada, contexto e 


\begin{tabular}{|c|l|}
\multicolumn{2}{|c|}{$\begin{array}{c}\text { relevância } \\
\text { Etapa 1 }\end{array}$} \\
\hline DURAÇÃO & 120 minutos (2 horas) \\
\hline OBJETIVOS DE \\
APRENDIZAGEM & $\begin{array}{l}\text { Conhecer e analisar as características do contexto de produção } \\
\text { das obras de Machado de Assis }\end{array}$ \\
\hline RECURSOS & $\begin{array}{l}\text { Quadro branco, pincel, computador, projetor e caixa de som, } \\
\text { documentário }\end{array}$ \\
\hline
\end{tabular}

\begin{tabular}{|c|c|c|c|}
\hline Atividades & Papel do aluno & Papel do professor & Avaliação \\
\hline $\begin{array}{l}\text { - Atividade dialogada com o } \\
\text { objetivo de levantar } \\
\text { conhecimentos prévios: } \\
\text { reflexão sobre quem foi } \\
\text { Machado de Assis. }\end{array}$ & 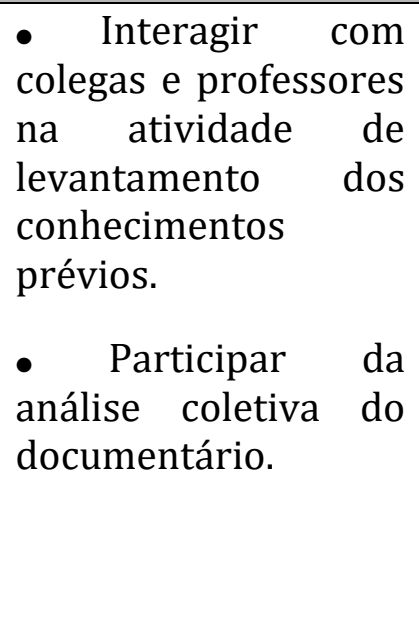 & 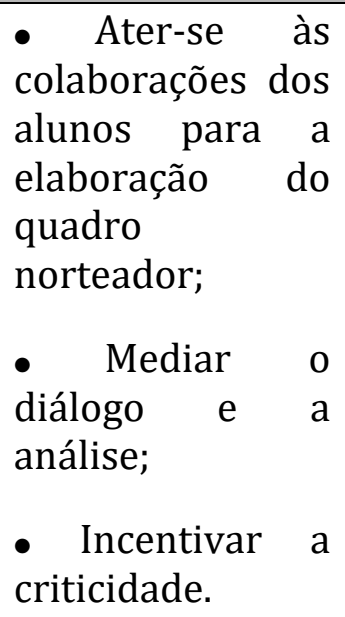 & $\begin{array}{l}\text { A avaliação } \\
\text { será } \\
\text { processual, } \\
\text { espera-se a } \\
\text { participaçã } \\
\text { o e } \\
\text { colaboraçã } \\
\text { o dos } \\
\text { estudantes. } \\
\text { - Diário de } \\
\text { aprendizag } \\
\text { em. }\end{array}$ \\
\hline
\end{tabular}

O primeiro momento considerou a apresentação do autor da obra que estudada. Essa conversa prévia serviu também como levantamento e ativação de conhecimentos prévios, além de permitir a interação no contexto de sala de aula. Esse momento inicial pode ser construído e incentivado a partir de algumas perguntas básicas tais como: quem foi o autor? Já tiveram algum contato com a vida e a obra de Machado de Assis? Qual a importância e relevância dele? 0 que esperam de uma aula sobre os contos de Machado de Assis? A partir disso, foi importante coletar algumas informações dadas pelos estudantes e anotá-las no quadro, criando, assim, uma linha norteadora do que já é sabido e conhecido.

É importante lembrar que a estratégia de levantamento e ativação de conhecimentos prévios precisa ser condizente com o conteúdo a ser ensinado e sua natureza. Como nesse contexto a intenção era saber o que os estudantes traziam como conteúdo factual, sugeriu-se que essa fase inicial fosse feita em uma roda de conversa. Entretanto, caso o interesse fosse fazer um diagnóstico inicial da compreensão leitora dos estudantes em 
relação aos textos de Machado de Assis, essa estratégia não seria bem-vinda. Seria necessário pensar em alguma atividade de leitura de texto machadiano para verificar como a turma se comportaria frente ao texto.

Após essa primeira conversa, para colaborar com as percepções dos estudantes e reflexões iniciais, a professora apresentou um documentário em curta-metragem chamado Mestres da Literatura - Machado de Assis: Um Mestre na Periferia, do Ministério da Educação, disponível em: < Machado de Assis - Vida e Obra $>$. Essa etapa pretendeu abordar percepções das mais diversas esferas, o que quer dizer que era esperado abordar as características da produção: as músicas, as imagens, o tempo, a autoria, as pessoas que são entrevistadas e suas características, as falas e suas relevâncias. 0 intuito, para além da apresentação de um recorte do que foi Machado de Assis, foi trabalhar com a criticidade dos estudantes.

Para trabalhar com o conto, a professora apresentou possibilidades de leitura: texto escrito, audiolivro ou vídeos. Essas possibilidades surgiram como forma de incentivo para que os(as) estudantes conhecessem a obra em um contexto mais amplo, que apontasse para a multimodalidade. Rojo $(\mathrm{s} / \mathrm{d})^{5}$ nos adverte de que, na vida contemporânea, os escritos e falas se misturam com imagens estáticas (fotos, ilustrações, gráficos, infográficos) e em movimento (vídeos) e com sons (sonoplastias, músicas). Nesse contexto, diferente da era do impresso, a palavra texto se estendeu a esses enunciados híbridos e hoje falamos também em textos orais e em textos multimodais, como as notícias televisivas e os vídeos de fãs no YouTube.

A primeira leitura do conto foi posta como uma atividade de casa, com o objetivo de que cada um(a) pudesse interagir com o texto. Na etapa 2, retoma-se a leitura do conto no formato de roda de conversa. Propõe-se que o(a) professor(a) entregue um texto para cada estudante ou disponibilize nas plataformas de acesso. $\mathrm{O}(\mathrm{a})$ professor(a) também pode sugerir que os estudantes busquem o texto no sítio domínio público.

Ao indicar o domínio público, foi possível, também, trabalhar com elementos da cultura digital e do mundo digital esclarecendo o que é esse sítio: 0 "Portal Domínio Público" foi lançado em novembro de 2004. Nele há o compartilhamento de conhecimentos por meio de uma biblioteca virtual. Seu principal objetivo é promover o amplo acesso às obras literárias, artísticas e científicas (na forma de textos, sons, imagens e vídeos), já em domínio público ou que tenham a sua divulgação devidamente autorizada, que constituem o patrimônio cultural brasileiro e universal. Portanto, ao acessar esse Portal, você tem acesso a informações confiáveis em um espaço seguro.

Além do site domínio público, também pode-se pensar em disponibilizar endereços eletrônicos nos quais seja possível encontrar o conto em áudio e em vídeo.

\footnotetext{
${ }^{5}$ Ver em: http://www.ceale.fae.ufmg.br/app/webroot/glossarioceale/verbetes/textos-multimodais
} 
Links:

Vídeo indicado: http://machado.mec.gov.br/videos-lista/item/2-mestres-daliteratura-machado-de-assis-um-mestre-na-periferia

Domínio

http://www.dominiopublico.gov.br/download/texto/bv000260.pdf

público:

Biblioteca sonora contos: https://www.youtube.com/watch?v=cDu-AS8bHE4

Destaca-se que, ao longo da sequência didática, os(as) estudantes registraram suas aprendizagens em um diário de itinerância. Todos(as) os(as) estudantes tiveram seus relatos diários das aulas, com reflexões. Registraram o que aprenderam em cada atividade, quais foram as dificuldades e o que precisaram fazer para superar essas dificuldades. Este diário serviu como instrumento individual de reflexão e de sistematização das aprendizagens adquiridas, também contribuindo para o amadurecimento do processo de aprendizagem, desenvolvendo nos(as) estudantes a metacognição.

\begin{tabular}{|c|l|}
\hline \multicolumn{2}{|c|}{$\begin{array}{c}\text { Núcleo 1: construção de reflexões iniciais a respeito da obra estudada, contexto e } \\
\text { relevância } \\
\text { Etapa } 2\end{array}$} \\
\hline DURAÇão & 60 minutos (1 hora) \\
\hline $\begin{array}{c}\text { Objetivos de } \\
\text { aprendizagem }\end{array}$ & $\begin{array}{l}\bullet \text { Reconhecer os elementos da narrativa no conto estudado } \\
\text { • Refletir sobre a obra considerando o contexto de produção } \\
\text { • Construir possibilidades acerca da história. }\end{array}$ \\
\hline Recursos & $\begin{array}{l}\text { Quadro branco, pincel, computador, projetor, caixa de som e } \\
\text { textos impressos. }\end{array}$ \\
\hline
\end{tabular}

\begin{tabular}{|c|c|c|c|}
\hline Atividades & Papel do aluno & $\begin{array}{l}\text { Papel do } \\
\text { professor }\end{array}$ & Avaliação \\
\hline $\begin{array}{l}\text { Dialogar sobre as } \\
\text { dificuldades, descobertas, } \\
\text { interesses e reflexões acerca } \\
\text { da leitura do conto Um } \\
\text { Homem Célebre. } \\
\text { - Analisar os elementos da } \\
\text { narrativa no conto }\end{array}$ & $\begin{array}{l}\text { - Relatar as percepções } \\
\text { quanto à leitura do } \\
\text { conto. } \\
\text { - Estabelecer relação } \\
\text { entre o contexto de } \\
\text { produção do conto e o } \\
\text { contexto }\end{array}$ & $\begin{array}{l}\text { - Mediar a } \\
\text { interação } \\
\text { entre os(as) } \\
\text { estudantes } \\
\text { acerca do } \\
\text { conto. } \\
\text { - Mediar a }\end{array}$ & $\begin{array}{l}\text { A avaliação } \\
\text { será } \\
\text { processual, } \\
\text { espera-se a } \\
\text { participação } \\
\text { e } \\
\text { colaboração } \\
\text { dos(as) }\end{array}$ \\
\hline
\end{tabular}




\begin{tabular}{|l|l|l|l|}
\hline contemporâneo & $\begin{array}{l}\text { análise } \\
\text { coletiva dos } \\
\text { elementos } \\
\text { da narrativa. } \\
\text { dos elementos da análise } \\
\text { narrativa, contribuindo } \\
\text { para uma construção } \\
\text { coletiva da turma. }\end{array}$ & $\begin{array}{l}\text { estudantes. } \\
\text { poderá fazer } \\
\text { roteiros } \\
\text { para } \\
\text { auxiliar a } \\
\text { análise dos } \\
\text { elementos } \\
\text { da } \\
\text { narrativa. }\end{array}$ \\
\hline
\end{tabular}

Com a leitura realizada, a professora pode mediar um diálogo a respeito da obra, procurando entender quais aspectos foram mais relevantes, o que os(as) estudantes acharam, se mudariam algo na história etc. Levou-se em consideração o fato de que uma parte dos(as) estudantes não conseguiu realizar a leitura, então foi papel da professora reforçar a importância de conhecer a obra. Esse diálogo foi feito no formato de roda de conversa, tendo como tema orientador as descobertas, os interesses e as dificuldades a partir da leitura do conto.

Além do diálogo sobre as obras, também foi elaborado um roteiro orientador para a análise dos elementos da narrativa. Esse roteiro serviu para guiar a turma em uma análise coletiva, que teve como resultado um mapa mental acerca do conto 0 Homem Célebre, de Machado de Assis. Para propor o trabalho com mapa mental, a professora apoiou-se em um livro específico sobre o tema disponível gratuitamente no link: http://www.idph.net/download/mmapresent.pdf

Ao final do núcleo 1, para introduzir as atividades do núcleo seguinte, a professora lançou o seguinte questionamento: vocês sabem o que é (re)mixagem? Conhecem memes, histórias alternativas, e-zines que gostariam de compartilhar com os(as) colegas? Assim os(as) estudantes levaram, para as aulas do núcleo 2, exemplos dessas produções.

Para maiores reflexões sobre novos letramentos e multiletramentos, indica-se a leitura do texto de Jaqueline Barbosa disponível no sítio plataforma do letramento: http://www.plataformadoletramento.org.br/em-revista-coluna-detalhe/1044/sobrenovos-e-multiletramentos-culturas-digitais-e-tecnologias-na-escola.html

\begin{tabular}{|c|lllll|}
\hline \multicolumn{1}{|c|}{ Núcleo 2: Introdução aos aspectos de retextualização, remixagem e apresentação do } \\
fanzine
\end{tabular}




\begin{tabular}{|l|l|}
\hline & $\begin{array}{l}\text { - Refletir sobre a presença de materiais remixados no contexto } \\
\text { contemporâneo da cultura digital } \\
\bullet \text { Analisar fanzines. }\end{array}$ \\
\hline Recursos & $\begin{array}{l}\text { Quadro branco, pincel, computador, projetor, caixa de som e } \\
\text { textos diversos impressos. }\end{array}$ \\
\hline
\end{tabular}

\begin{tabular}{|c|c|c|c|}
\hline Atividades & Papel do aluno & $\begin{array}{ll}\text { Papel do } & \text { do } \\
\text { professor }\end{array}$ & Avaliação \\
\hline $\begin{array}{l}\text { - Roda de conversa para } \\
\text { compartilhamento de } \\
\text { materiais remixados } \\
\text { - Construção coletiva e } \\
\text { colaborativa de um quadro } \\
\text { com as características desses } \\
\text { materiais } \\
\text { - Construir os conceitos de } \\
\text { remixagem, com base nesse } \\
\text { quadro. } \\
\text { - Analisar fanzines }\end{array}$ & $\begin{array}{l}\text { - Compartilhar os } \\
\text { materiais remixados e } \\
\text { apresentá-los } \\
\text { brevemente } \\
\text { Participar da } \\
\text { construção do quadro } \\
\text { com as características } \\
\text { desses materiais e da } \\
\text { construção dos } \\
\text { conceitos }\end{array}$ & $\begin{array}{l}\text { - Compartilhar } \\
\text { materiais } \\
\text { remixados } \\
\text { - Mediar a } \\
\text { construção do } \\
\text { quadro com as } \\
\text { características } \\
\text { dos materiais } \\
\text { - Mediar a } \\
\text { construção dos } \\
\text { conceitos } \\
\text { - Apresentar } \\
\text { exemplos de } \\
\text { fanzine e } \\
\text { analisar com a } \\
\text { turma }\end{array}$ & $\begin{array}{l}\text { A avaliação } \\
\text { será } \\
\text { processual, } \\
\text { espera-se a } \\
\text { participação } \\
\text { na roda de } \\
\text { conversa, } \\
\text { com a } \\
\text { apresentaçã } \\
\text { o dos } \\
\text { materiais, e } \\
\text { a } \\
\text { colaboração } \\
\text { dos(as) } \\
\text { estudantes } \\
\text { na } \\
\text { construção } \\
\text { do quadro e } \\
\text { dos } \\
\text { conceitos. }\end{array}$ \\
\hline
\end{tabular}

O segundo núcleo teve o objetivo de construir os conceitos da remixagem, para isso fezse necessário apresentar as características dessa prática muito presente na cultura digital. Para essa atividade, estudantes e professora participaram de uma roda de conversa para discutir sobre esses materiais. Memes, histórias alternativas, e-zines, foram levados para a sala de aula pelo grupo de estudantes com o intuito de exemplificar e explicar a cultura remix.

A cultura digital se manifesta naquilo que Navas define como "cultura remix", isto é, "uma atividade global que consiste na troca criativa e eficiente de informações, 
possibilitada pelas tecnologias digitais e apoiada nas operações de recortar/copiar e colar" (NAVAS, 2010, p. 159, apud Buzato et al, 2013). 0 autor destaca, ademais, que a característica fundamental de todo remix é sua filiação a uma obra original, a qual se reporta de alguma maneira, com graus variados de diferenciação. Para ter acesso ao estado da arte sobre cultura remix, indica-se a leitura do artigo intitulado Remix, mashup, paródia e companhia: por uma taxonomia multidimensional $d a$ transtextualidade na cultura digital, de Buzato et al, disponível na plataforma scielo:

http://www.scielo.br/scielo.php?script=sci arttext\&pid=S1984-63982013000400011

As características desses materiais e o conceito de remixagem emergiram dessa atividade, que deu subsídios para a construção de um quadro com essas informações.

Construído isso, a professora mostrou exemplos de fanzines e contextualizou com as seguintes questões: i) o que são fanzines; ii) como surgiram; iii) como eram feitas; iv) quando começaram a surgir no Brasil; v) como expor sua fanzine; vi) como confeccionar fanzines on-line; vii) como divulgar sua fanzine on-line. Esse momento foi expositivo-dialogado e teve o objetivo de familiarizar os(as) estudantes para o processo final da proposta.

Se o(a) professor(a) quiser conhecer experiências com fanzine na sala de aula, poderá ler o relato intitulado "Fanzine na sala de aula: uma proposta pedagógica de incentivo à produção textual”, disponível em:

http://www.ufrgs.br/revistabemlegal/edicoes-anteriores/Vol\%2C6\%20n.2/fanzinena-sala-de-aula-uma-proposta-pedagogica-de-incentivo-a-producao-textual

\begin{tabular}{|l|l|}
\hline \multicolumn{2}{|c|}{ Núcleo 3: Elaboração e divulgação do produto final } \\
\hline DURAÇÃO & 180 minutos (3 horas) \\
\hline $\begin{array}{l}\text { Objetivos } \\
\text { aprendizagem }\end{array}$ & $\begin{array}{l}\bullet \text { Retextualizar contos } \\
\bullet \text { Criar fanzines }\end{array}$ \\
\hline Recursos & $\begin{array}{l}\text { Quadro branco, pincel, computador, projetor, caixa de som e } \\
\text { textos diversos impressos, materiais para artesanato, jornais, } \\
\text { folhas, tesouras, revistas, cola, lápis e canetas. }\end{array}$ \\
\hline
\end{tabular}

\begin{tabular}{|l|l|l|l|}
\hline Atividades & Papel do aluno & $\begin{array}{l}\text { Papel do } \\
\text { professor }\end{array}$ & Avaliação \\
\hline $\begin{array}{l}\text { - Aula expositiva-dialogada } \\
\text { sobre atividade de }\end{array}$ & $\begin{array}{l}\text { Produzir uma fanzine } \\
\text { com o tema do conto }\end{array}$ & $\begin{array}{l}\text { - Realizar a aula } \\
\text { expositiva- }\end{array}$ & $\begin{array}{l}\text { A avaliação } \\
\text { será }\end{array}$ \\
\hline
\end{tabular}




\begin{tabular}{|c|c|c|c|}
\hline $\begin{array}{l}\text { retextualização } \\
\text { - Produzir uma fanzine com } \\
\text { o tema do conto de Machado } \\
\text { de Assis, Um Homem } \\
\text { Célebre. }\end{array}$ & $\begin{array}{l}\text { de Machado de Assis, } \\
\text { Um Homem Célebre. }\end{array}$ & $\begin{array}{l}\text { dialogada para } \\
\text { subsidiar a } \\
\text { atividades de } \\
\text { retextualização } \\
\text { - Colaborar com } \\
\text { instruções, } \\
\text { materiais para a } \\
\text { produção de } \\
\text { fanzines }\end{array}$ & $\begin{array}{l}\text { processual, } \\
\text { espera-se a } \\
\text { participação } \\
\text { dos(as) } \\
\text { estudantes e } \\
\text { apresentaçã } \\
\text { o das } \\
\text { Fanzines. }\end{array}$ \\
\hline
\end{tabular}

Para finalização deste ciclo de aulas, foi proposta uma retextualização. Entende-se retextualização como o processo de produção de um novo texto a partir de um ou mais textos-base, implicando modificações profundas no texto, em função da alteração dos propósitos comunicativos ou dos gêneros envolvidos na atividade. (ver explicação em: http://www.ceale.fae.ufmg.br/app/webroot/glossarioceale/verbetes/retextualizacao

A atividade de retextualização foi realizada em formato de oficina para a produção de uma fanzine com a temática do conto Um Homem Célebre, de Machado de Assis, previamente lido pelos estudantes. Para isso, a professora levou materiais para colaborar com a produção das zines off-line, formato escolhido para essa oficina, porém a proposta pode ser realizada de forma on-line também. Os materiais utilizados foram: jornais, revistas, folhas coloridas, lápis colorido, giz de cera, tesouras, pincéis, cola, etc. Ao trabalhar com a perspectiva da criação on-line, é importante pensar em ferramentas e plataformas acessíveis e explicativas disponíveis como recursos abertos.

Finalizado o processo de elaboração, os estudantes puderam trocar suas fanzines, com o intuito de fazê-las circular assim como acontece na produção popular. Foi possível também fazer uma exposição na biblioteca da escola.

Ao final da sequência didática, a professora organizou uma roda de conversa para compartilhamento de leituras dos diários de itinerância. Esse diário, juntamente com as atividades desenvolvidas ao longo da sequência, constituíram o processo avaliativo.

\section{Considerações finais}

A pesquisa referida, que também envolveu a aplicação de sequências didáticas, tal como exposto neste relato, trouxe como uma das principais contribuições o fato de os estudantes de ensino médio indicarem que aprendem melhor as questões relacionadas à disciplina de português com atividades mais interativas, dinâmicas, em que sejam colocados como sujeitos no processo. 
As sequências didáticas desenvolvidas no projeto partiram de experiências de observação de contextos de sala de aula. Assim, para a elaboração das oficinas, levouse em consideração a perspectiva pedagógica dos multiletramentos e do ensino híbrido nos contextos observados. As propostas podem ser consideradas uma experiência inicial de inserção gradativa da pedagogia dos multiletramentos e do ensino híbrido nos currículos da educação básica.

Dessa forma, a partir da experiência com a proposta didática, constatamos que associar elementos da cultura digital ao ensino da literatura favoreceu o desenvolvimento da autoria nos estudantes, bem como a criatividade e a originalidade. Assim, essa experiência demonstra que o desenvolvimento do trabalho pedagógico, considerando a perspectiva dos multiletramentos, pode auxiliar a ressignificar o ensino de literatura no contexto escolar contemporâneo.

\section{Referências}

ASSIS, MACHADO DE. Um homem célebre. Disponível em: http://www.dominiopublico.gov.br/download/texto/ua000232.pdf. Acesso em: 20/11/2019.

BARBOSA, J. P. Sobre novos e multiletramentos, culturas digitais e tecnologias na escola. Disponível em: http://www.plataformadoletramento.org.br/em-revistacoluna-detalhe/1044/sobre-novos-e-multiletramentos-culturas-digitais-etecnologias-na-escola.html. Acesso em: 12/03/2020.

BACICH, L.; MORAN, J. Aprender e ensinar com foco na educação híbrida. Revista Pátio, $\mathrm{n}$ o 25, junho, 2015, p. 45-47. Disponível em: http://www2.eca.usp.br/moran/wp-content/uploads/2015/07/hibrida.pdf. Acesso em: 4/6/2020.

BUZATO, Marcelo El Khouri et al. Remix, mashup, paródia e companhia: por uma taxonomia multidimensional da transtextualidade na cultura digital. Rev. bras. linguist. apl. [online]. 2013, vol.13, n.4, pp.1191-1221. Disponível em: https://www.scielo.br/scielo.php?pid=S198463982013000400011\&script=sci abstract\&tlng=pt. Acesso em: 20/03/2020.

CANDAU, V. M. et al. Oficinas pedagógicas de direitos humanos. RJ: Vozes, 1995

PEREIRA, E. C. Práticas letradas digitais e os desafios da escola pública. In: BAPTISTA, L. M. T. R. (Org.) Autores e produtores de textos na contemporaneidade: multiletramentos, letramento crítico e ensino de línguas. Campinas, SP: Pontes Editores, 2016. p. 153-181.

PESSOA, Ana Cláudia Gonçalves. Sequência didática. Universidade Federal de 
Pernambuco (UFPE) / Centro de Estudos em Educação e Linguagem (CEEL). Disponível em: http://ceale.fae.ufmg.br/app/webroot/glossarioceale/verbetes/sequencia-didatica. Acesso em: 29/05/2020.

ROJO, R. Entre plataformas, odas e protótipos: novos multiletramentos em tempos de web. Descrição, Ensino e Aprendizagem, Vol. 38 No. 1 jan-jul 2017. Disponível em: https://revistas.pucsp.br/esp. Acesso em: 03/06/2020.

ROJO, Roxane; MOURA, Eduardo. Multiletramentos na escola. São Paulo: Parábola, 2012. 